\title{
西双版纳热带季节雨林林冠穿透雾水的观测研究
}

\author{
刘文杰 ${ }^{1,2}$ 张一平 ${ }^{1}$ 刘玉洪 ${ }^{1}$ 李红梅 ${ }^{1}$ 段文平 ${ }^{1}$ \\ (1 中国科学院西双版纳热带植物园, 云南预腊 666303)(2 中国科学院生态环境研究中心, 北京 100085)
}

摘 要 利用 4 年( 1999 2002 年) 的林冠穿透雾水观测资料, 对西双版纳热带季节雨林林冠穿透雾水进行了研究。 全年林冠穿透雾水达 $(89.4 \pm 13.5) \mathrm{mm}$ (平均值 \pm 标准差)(雾季和干热季共占 $85.9 \% \pm 6.6 \%$ ), 为全年降水量(穿透 雾水 + 雨水) 的 $4.9 \% \pm 1.7 \%$ 。全年水平降水(穿透雾水 + 截留雾水)共 $(337.9 \pm 18.3) \mathrm{mm}$, 占总降水 (穿透雾水 + 截留雾水 + 雨水) 的 $16.4 \% \pm 1.0 \%$ 。年林冠穿透雾水与年降雨量呈负相关关系。月林冠穿透雾水与月均最低气 温呈显著的负相关, 与月均相对湿度、月均 0:00 10:00 风速及月雾日数呈显著的正相关。全年 68\% 5 5\% 的有雾 天气里可以收集到林冠穿透雾水 $\left((0.38 \pm 0.27) \mathrm{mm} \cdot \mathrm{d}^{-1}\right)$, 且日穿透雾水量、穿透雾水强度与气温和风速呈显著的 相关, 即气温越低、风速越大, 日穿透雾水量、穿透雾水强度越大。对本地区热带雨林生态系统的健康生长和维持 而言, 雾及雾水极大地弥补了降雨量的不足, 且降雨量少的年份, 雾的这种作用似乎更为重要。

关键词 水平降水 穿透雾水 截留雾水 热带季节雨林 西双版纳

\section{FOG THROUGHFALL AT A SEASONAL RAIN FOREST IN XISHUANGBANNA, SOUTHWEST CHINA}

\author{
LIU Wen-Jie ${ }^{1,2}$ ZHANG Yi-Ping ${ }^{1} \quad$ LIU Yu-Hong ${ }^{1} \quad$ LI Hong-Mei ${ }^{1}$ and DUAN Wen-Ping ${ }^{1}$ \\ (1 Xishuangbanna Tropical Botanical Garden, the Chinese Academy of Sciences, Mengla, Yunnan 666303, China) \\ (2 Research Centre for Eco-environmental Sciences, the Chinese Academy of Sciences, Beijing 100085, China)
}

\begin{abstract}
Fog throughfall and related microclimatic factors were measured between November 1998 and February 2003 at a tropical seasonal rain forest in Xishuangbanna, Southwest China. Twelve bottle-funnel collectors were set in a random pattern on the forest floor to determine the daily amount of fog throughfall, and two funnel collectors connected with polyethylene tubing to a mechanical recording siphon-raingauge were used to determine fog throughfall intensity and temporal character. Related microclimatic variables including air temperature, relative humidity, wind speed, solar radiation and rainfall were also recorded by a meteorological observation system mounted on a $72 \mathrm{~m}$ meteorological tower in the study site. During the study period, absolute amounts of mean annual fog throughfall were up to $(89.4 \pm 13.5) \mathrm{mm}$ ( mean $\pm S D)$, contributing $4.9 \% \pm$ $1.7 \%$ of the annual precipitation, with $85.9 \% \pm 6.6 \%$ of the fog throughfall collected in the foggy season (November-February) and dry-hot season (March-April). The amounts of annual fog throughfall plus fog interception accounted for $16.4 \% \pm 1.0 \%$ of total annual precipitation which includes fog throughfall, fog interception and rainfall. The annual fog throughfall was negatively correlated with annual rainfall, demonstrating that the dependence on fog as an additional water input was highest in the year when rainfall was lowest but fog throughfall was high. Monthly variation in fog throughfall was different from rainfall patterns and negative correlation was found between monthly average minimum air temperature and monthly fog throughfall while positive correlations were found between monthly fog throughfall and monthly average relative humidity, monthly average wind speed during 0:00-10:00, and monthly sum of fog-days. In fog-drip occurring days, the average fog throughfall was $(0.38 \pm 0.27) \mathrm{mm} \cdot \mathrm{d}^{-1}$ and the amounts of fog throughfall per day and throughfall intensity were negatively correlated with air temperature and positively correlated with wind speed. The results suggest that fog, which not only inputs water into the forest but also partly reduces the evapotranspiration of the forest, plays an important role in the hydrology of the forest, especially in the foggy and dry-hot seasons. Therefore, neglect of the contribution from horizontal precipitation ( fog throughfall plus fog interception) will make calculations of the water balance inaccurate in the forest. These results also demonstrate the importance of understanding the impacts of climate factors, and have important implications for ecologists and hydrologists interested in fog-inundated ecosystems and the plants that inhabit them.
\end{abstract}

Key words Horizontal precipitation, Fog throughfall, Fog interception, Tropical seasonal rain forest, Xishuangbanna 
多雾的山地和沿海森林生态系统中, 雾降水 (Fogwater, Occult precipitation, and Horizontal precipitation) 一直被认为是一种极其重要的水文和化学输 入项, 其生态效应是多方面的 (Dallard et al. , 1983; Unsworth \& Crossley, 1987; Asbury et al., 1994; Ishibashi \& Terashima, 1995; Monteith \& Unsworth, 1990; Ingraham \& Matthews, 1988)。雾的形成不仅凝 结水汽 ( Ingraham \& Matthews, 1988 )、沉降养分 (Weathers \& Likens, 1997) 进入森林, 同时也释放了 凝结潜热而减弱了降温强度 (刘文杰等, 2001a), 还 缩短了日照时数而消减蒸发散, 这对缓解植物干旱、 补充养分不足、减弱因低温加剧的光抑制等方面具 有重要作用 ( Ishibashi \& Terashima, 1995)。由于雾 水作为森林水文、化学循环的关键环节而影响养分 循环模式 (Weathers \& Likens, 1997), 因而频繁的雾 是决定某些山地和沿海森林分布及特征的重要因 子, 尤其是在热带森林分布地区 (Gordon et al., 1994a)。例如, 低地山地雨林 (Lower montane rainforest) 总是被频繁的雾弥漫, 而高地山地雨林 (Upper montane rainforest) 则更多地被频繁、持久的雾所笼 罩, 这两种森林均被称为热带山地多雾林 (Tropical montane cloud forest)(Grubb \& Whitemore, 1966)。这 些热带山地多雾林林冠穿透雾水可达全年降水量 (雨水 + 雾水) 的 $2.4 \% \sim 60.6 \%$ (Cavelier \& Goldstein, 1989; Cavelier et al., 1996), 而雾水中化学离 子浓度为雨水中相应离子的 2 24 倍 (Asbury et al., 1994; Clark et al., 1998a; Gordon et al., 1994a; 1994b; Weathers \& Likens, 1988), 可提供全年 养分输入 (雨水 + 雾水)的 $8 \% \sim 30 \%$ (Asbury et al., 1994)。

西双版纳热带雨林是在水分、热量、海拔均达到 极限条件下的热带北缘季节雨林群落, 由于地处山 原地貌和季风气候特点的热带北缘, 热带雨林受到 了季节干旱和冬季低温的影响 (朱华, 1992)。本区 属西南季风气候区, 年降雨量 $1500 \sim 1600 \mathrm{~mm}$, 但 雾季( $11 \sim 2$ 月)和干热季( $3 \sim 4$ 月)雨量偏少, 不足 全年的 13\%。尤其是 3 4 月, 气温升至全年最高, 植物需水量大为增加。但本区是有名的静风( 年均 风速 $0.5 \mathrm{~m} \cdot \mathrm{s}^{-1}$ )、多雾 (年雾日 > $170 \mathrm{~d}$ ) 区, 雾季和 干热季多有辐射雾出现, 雾的总持续时间占雾季和 干热季时间的 40\%以上(刘文杰等, 1996), 尤其是在 热带雨林覆盖区, 辐射雾更是频繁出现。因而, 雾所 塑造的温湿环境必然对热带雨林的生存和发展起到 一定的作用。然而, 有关西双版纳地区热带雨林林
内水平降水的研究几乎为空白。刘文杰等 (2001b) 对本区热带季节雨林林冠穿透雾水的研究结果表 明: 在干热季有雾的夜间, 林下穿透雾水可达 0.39 $\mathrm{mm} \cdot \mathrm{d}^{-1}$, 但并未对全年林冠穿透雾水状况进行研 究。本文利用 1999 年 11 月至 2003 年 2 月在热带季 节雨林内观测的林冠穿透雾水和环境因子的资料, 研究林冠穿透雾水特征及其影响因子, 为热带森林 内雾水的水文和化学效应及水分和养分循环规律的 深入研究提供参考。

\section{1 样地自然环境及群落特征}

观测点设在中国生态系统研究网络西双版纳热 带季节雨林定位观测样地 (热带季节雨林面积约 3 $\left.\mathrm{km}^{2}\right)$ 内 $\left(21^{\circ} 56^{\prime} \mathrm{N}, 101^{\circ} 15^{\prime} \mathrm{E}\right.$ ), 海拔 $750 \mathrm{~m}$, 观测点与 雨林边缘平坝区相对高差约 $150 \mathrm{~m}$ 。本区属热带北 缘西南季风气候, 一年中有干季( 包括雾季 ( $11 \sim 2$ 月)、干热季 ( $3 \sim 4$ 月))、雨季 ( $5 \sim 10$ 月)之分(张克 映, 1963)。年均气温 $21.7{ }^{\circ} \mathrm{C}$, 年均风速 $0.7 \mathrm{~m} \cdot \mathrm{s}^{-1}$, 相对湿度 $86 \%$, 年降雨量 $1700 \mathrm{~mm}$, 其中雨季占 $83 \% \sim 87 \%$, 干季占 $13 \% \sim 17 \%$ 。

观测样地所在的热带季节雨林, 其群落高度 $35 \mathrm{~m}$ 左右, 乔木层按高度可分为 3 层: 上层优势种为 番龙眼 ( Pometia tomentosa)、千果榄仁 ( Terminalia myriocarpa); 中层常见种有云南玉荵 (Barringtonia macrostachya)、大叶白颜树 (Gironniera subaequalis)、山 蕉( Mitrephora maingayi) 等; 下层树种主要有染木 (Saprosma ternatum)、狭叶巴戟( Morinda angustifoli$a$ )、玉叶金花 (Mussaenda sp.) 等, 群落结构特征详见 文献 (Cao \& Zhang, 1996)。

\section{2 研究方法}

在热带季节雨林林下距地表 $0.7 \mathrm{~m}$ 高处水平随 机架置 12 个口径 $0.8 \mathrm{~m}$ 的圆形漏斗, 各漏斗出水口 处悬挂 $1000 \mathrm{ml}$ 的塑料瓶承接穿透雾水。塑料瓶内 $503 \mathrm{ml}$ 承接水换算到单位面积上等于 $1 \mathrm{~mm}$ 的穿透 雾水。每日 9:00 左右(林冠无雾水滴落时)测定穿 透雾水量( 1998 年 11 月开始), 日穿透雾水量取 12 个漏斗承接水的平均值。1 999 年 1 2 月, 将两个漏 斗承接的穿透雾水用塑料管 (口径 $1 \mathrm{~cm}$ ) 导入虹吸 自记雨量计中进行自动记录, 测定林冠穿透雾水强 度和时间动态变化。采用小气候梯度观测法, 将 MAOS-1 全自动小气候观测系统(包括 4 层温度、湿 度、风速; 1 层土壤热通量、辐射各分量、管状辐射 表、雨量计) (长春气象仪器研究所生产)安装在热带 
季节雨林定位样地梯度观测铁塔上 (塔高 $72 \mathrm{~m}$ ), 观 测小气候要素变化特征。针对热带季节雨林 3 个乔 木冠层 I、II 、III (简称冠层 I 、冠层 II 、冠层 III , 高分 别约 $33 \mathrm{~m} 、 20 \mathrm{~m} 、 5 \mathrm{~m}$ ), 在冠层 I 以上 $0.5 \mathrm{~m}$ 布设一 层温、湿、风传感器及辐射传感器 (总辐射、反射辐 射、净辐射), 在冠层 II 、冠层 III 以上 $0.5 \mathrm{~m}$ 及铁塔顶 部各布设一层温、湿、风传感器, 翻斗雨量计水平安 置在铁塔顶部测定降雨量 (采集频度 1 次 $\cdot \mathrm{h}^{-1}, 1997$ 年 11 月开始观测)。雾日定义为水平能见度 $<1 \mathrm{~km}$
及至少持续 15 min（Gordon et al.，1994b）。

\section{3 结 果}

\section{1 林冠穿透雾水量和降雨量的年变化}

热带季节雨林内全年林冠穿透雾水达 ( $89.4 \pm$ 13.5) $\mathrm{mm}$ (平均值 \pm 标准差), 为全年降水量 (穿透 雾水 + 雨水) 的 $4.9 \% \pm 1.7 \%$ (表 1 )。由 4 年观测 的年林冠穿透雾水和降雨变化 (图 1a) 可看出, 2002年的降雨最多 (1948.7 mm), 其穿透雾水最少

表 1 热带季节雨林内各季节平均穿透雾水量和降雨量分布 (1999 2002 年)

Table 1 Seasonal variation of fog throughfall and rainfall in the tropical seasonal rain forest $(1999-2002)$

\begin{tabular}{|c|c|c|c|c|}
\hline 项目 & 雾季 & 干热季 & 雨季 & 全年 \\
\hline Items & Foggy season & Dry-hot season & Rainy season & Whole year \\
\hline 穿透雾水 Fog throughfall（mm） & $56.2 \pm 5.2$ & $20.6 \pm 4.0$ & $12.6 \pm 2.4$ & $89.4 \pm 13.5$ \\
\hline 降雨量 Rainfall (mm) & $114.7 \pm 34.3$ & $62.2 \pm 18.3$ & $1531.3 \pm 182.0$ & $1717.8 \pm 206.2$ \\
\hline $\begin{array}{l}\text { 穿透雾水/(降雨量 + 穿透雾水) } \\
\text { Fog throughfall/(Rainfall + Fog throughfall })(\%)\end{array}$ & $32.9 \pm 4.2$ & $24.9 \pm 2.7$ & $0.8 \pm 0.2$ & $4.9 \pm 1.7$ \\
\hline
\end{tabular}

表内数据为平均值 \pm 标准差, 样本数为 4 Entries are means \pm standard deviation $(\mathrm{SD})(n=4)$

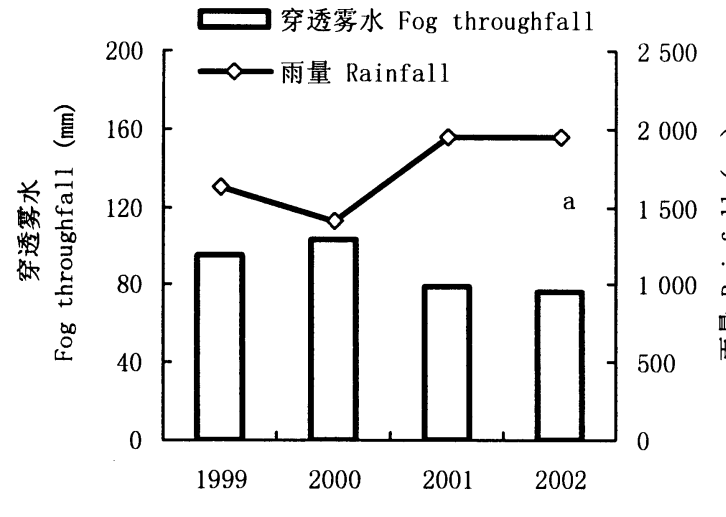

年 Year

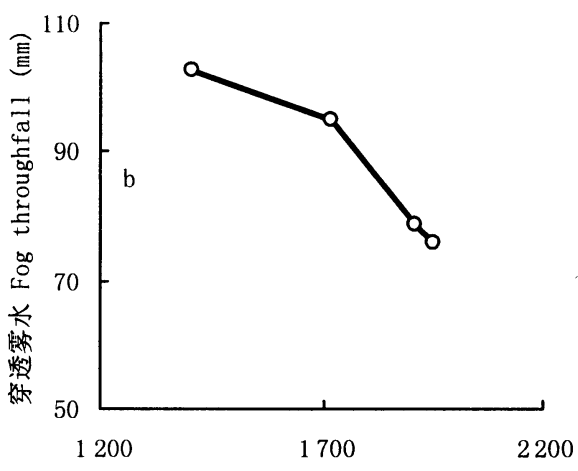

雨量 Rainfall (mm)

图 1 热带季节雨林内年穿透雾水量和降雨量变化 (a)及其关系 $(\mathrm{b})$

Fig.1 Variation (a) and relationship (b) between annual fog throughfall and rainfall for the tropical seasonal rain forest

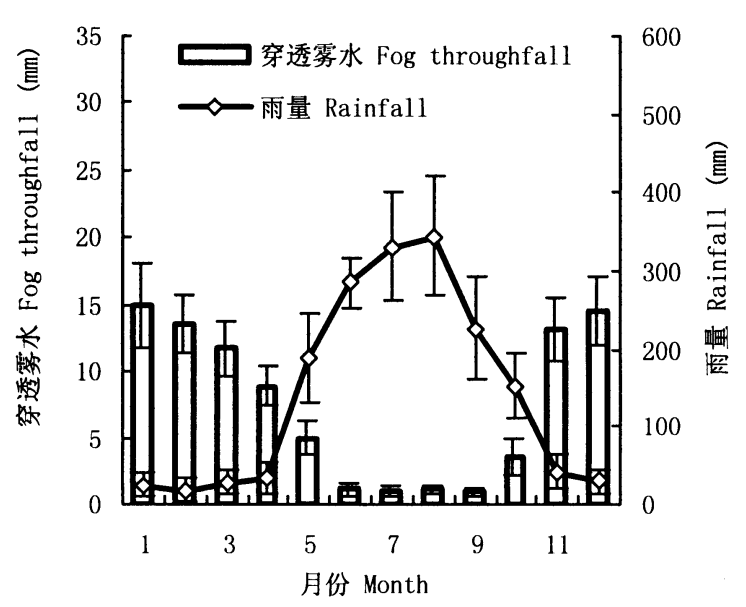

图 2 热带季节雨林内平均各月降雨量和穿透雾水量(1999 2002 年) Fig.2 Mean rainfall and fog throughfall each month for the tropical seasonal rain forest from 1999 to 2002
(75.9 mm); 2000 年降雨最少 (1 $405.5 \mathrm{~mm}$ ), 其穿透 雾水最多 $(102.9 \mathrm{~mm})$ 。年林冠穿透雾水量与降雨量 具有负相关关系(图 1b)。因而, 对此热带季节雨林 而言,雾水在雨水较少的年份可能具有更为重要的 意义。

\section{2 林冠穿透雾水量和降雨量的季节变化}

月降雨量与月穿透雾水量呈相反的分配状况 (图 2)。雨季 ( $5 \sim 10$ 月)各月降雨量多, 但穿透雾水 量较少; 雾季( $11 \sim 2$ 月)和干热季( $3 \sim 4$ 月)各月降 雨较少, 但穿透雾水量较多。雾季和干热季, 林冠穿 透雾水量共占全年总穿透雾水量的 $85.9 \% \pm 6.6 \%$ $((76.8 \pm 7.2) \mathrm{mm})$, 而雾季相应就占 $62.9 \% \pm 4.8 \%$ $((56.2 \pm 5.2) \mathrm{mm})$ (表 1$)$ 。由表 1 可看出, 雾季的穿 透雾水量可占本季节降水量的 $32.9 \% \pm 4.2 \%$, 而 干热季和雨季则依次减小。 
夜间或清晨, 气温越低、相对湿度越高, 雾越容 易形成、越浓重。风速越大, 则随风携带的雾滴被林 冠截留的量将越多(Oke，1978; Unsworth \& Crossley, 1987)。因而,在干季(雾季和干热季), 月穿透雾水 量与月均最低气温呈明显的负相关, 与月均相对湿 度、月均 0:00 10:00 风速及月总雾日数呈明显的 正相关 (图 3, $p<0.001$ )。雨季同样有此相关性 $(p<0.001)$, 但雨季和干季的相对湿度与穿透雾水 量的关系是无法同时比较的,因为对干季而言,雨季 高的相对湿度并不能导致多的穿透雾水量。
3.3 林冠穿透雾水量的日变化

雾季, $92 \% \pm 6 \%$ 的有雾天气里能够收集到林冠 穿透雾水, 平均可达 $(0.52 \pm 0.37) \mathrm{mm}^{\bullet} \mathrm{d}^{-1}$, 而干热 季和雨季的相应值则依次减小 (表 2)。就全年能够 收集到穿透雾水的次数而言, 其平均值为 $(0.38 \pm$ $0.27) \mathrm{mm} \cdot \mathrm{d}^{-1}$ 。日穿透雾水与当日最低气温呈明显 的负相关 $(p<0.001)$ 与当日 $0: 00 \sim 10: 00$ 的平均风 速呈明显的正相关 (图 $4, p<0.001$ )。穿透雾水强 度与当时的气温和风速同样具有这种明显的相关性 (图 $5, p<0.001$ ), 即气温越低、风速越大, 日穿透雾

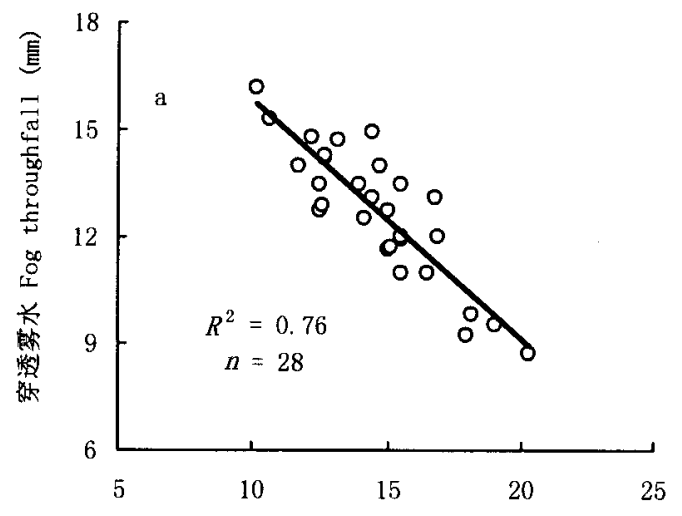

温度 Temperature $\left({ }^{\circ} \mathrm{C}\right)$

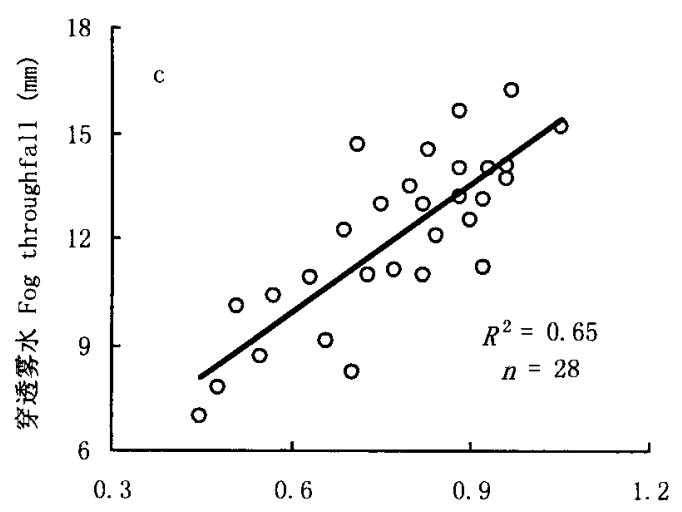

风速 Wind speed $\left(m \cdot \mathrm{s}^{-1}\right)$

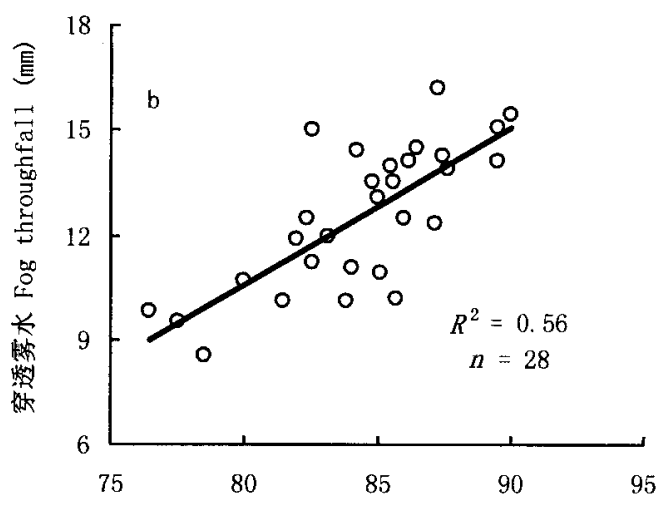

相对湿度 Relative humidity (\%)

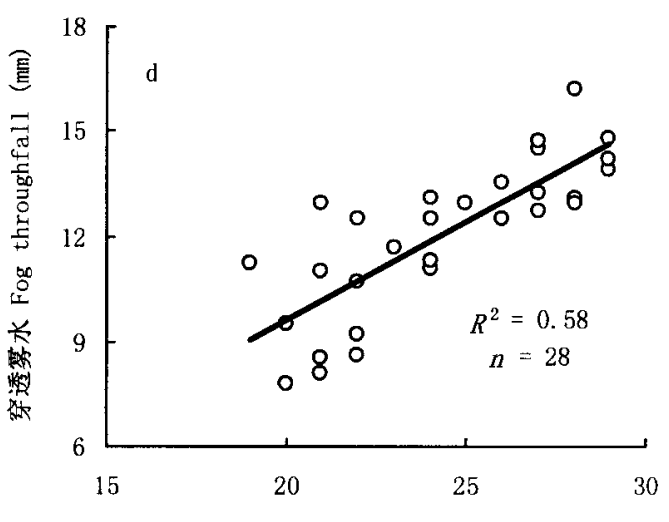

雾日数 Fog days (d)

图 3 月穿透雾水量与月均最低气温 (a)、月均相对湿度 (b)、月均 0:00 10:00 风速 (c)及月雾日数 (d) 的关系

Fig.3 Relationships between monthly fog throughfall and monthly average minimum air temperature (a), monthly average relative humidity (b), monthly average wind speed during 0:00 10:00 (c) and, monthly sum of fog-days (d)

表 2 热带季节雨林各季节平均日穿透雾水量及可收集到雾水的雾日比率 (1999 2002 年)

Table 2 Seasonal average fog throughfall per day in fog-drip occurring days and average percentage of fog-drip occurring days of total fog-days in the tropical seasonal rain forest $(1999-2002)$

\begin{tabular}{lcccc}
\hline \multicolumn{1}{c}{ 项目 } & 雾季 & 干热季 & 雨季 & 全年 \\
Items & Foggy season & Dry-hot season & Rainy season & Whole year \\
\hline 穿透雾水 Fog throughfall $\left(\mathrm{mm}^{\bullet} \mathrm{d}^{-1}\right)$ & $0.52 \pm 0.37$ & $0.41 \pm 0.38$ & $0.22 \pm 0.15$ & $0.38 \pm 0.27$ \\
FD $(\%)$ & $92 \pm 6$ & $82 \pm 4$ & $36 \pm 5$ & $68 \pm 5$ \\
\hline
\end{tabular}

FD 为收集到雾水的雾日占季节总雾日的比率 FD represents average percentage of fog-drip occurring days of total fog days 表内数据为平均值 \pm 标准差, 样本数为 4 Entries are means \pm standard deviation $(\mathrm{SD})(n=4)$ 

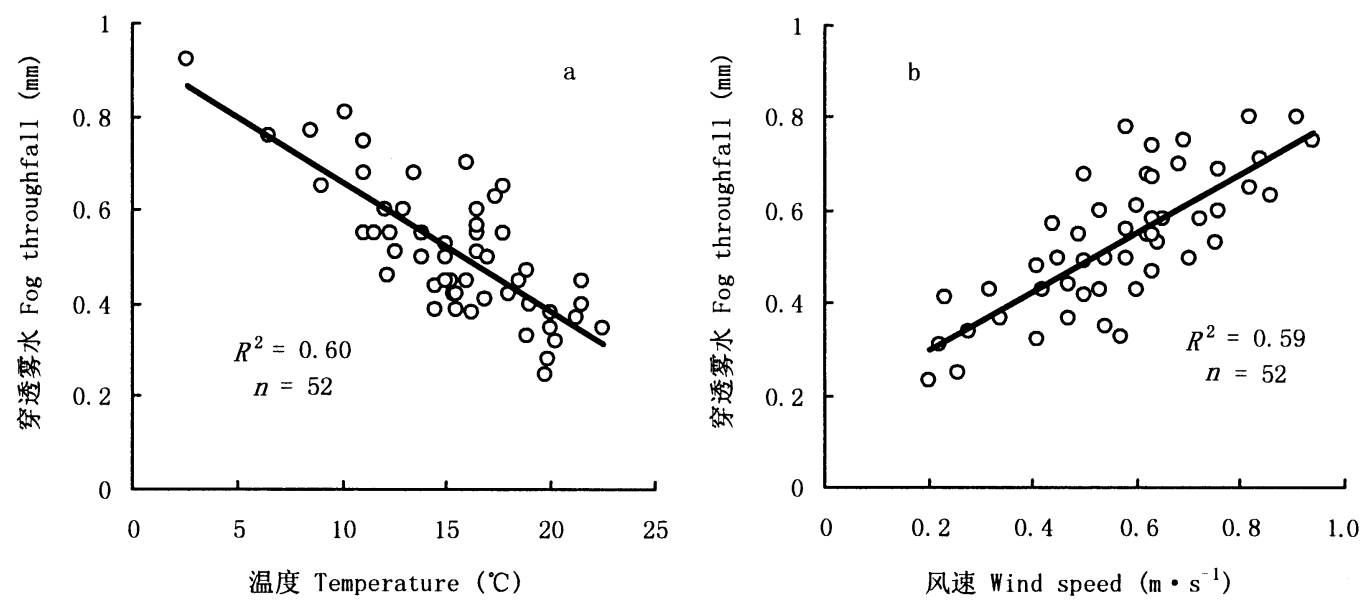

图 4 日穿透雾水量与日最低气温 (a) 和 0:00 10:00 平均风速 (b)的关系

Fig.4 Relationships between diurnal fog throughfall and minimum air temperature (a) and, average wind speed during 0:00 10:00 (b)
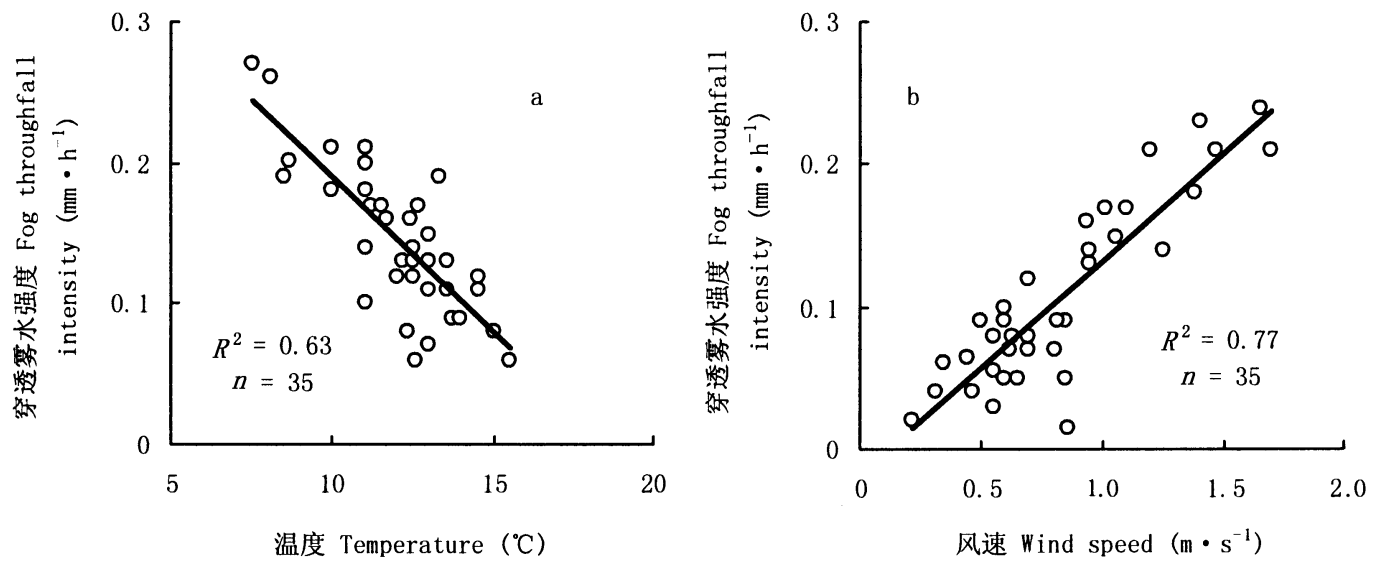

图 5 穿透雾水强度与气温 $(\mathrm{a})$ 和风速 $(\mathrm{b})$ 的关系

Fig.5 Relationships between fog throughfall intensity and air temperature (a) and, wind speed (b)

水量、穿透强度越大。

\section{4 结论和讨论}

西双版纳热带季节雨林全年林冠穿透雾水达 $(89.4 \pm 13.5) \mathrm{mm}$ (雾季和干热季共占 $85.9 \% \pm$ $6.6 \%$ ), 占全年降水量 (穿透雾水 + 雨水) 的 $4.9 \%$ $\pm 1.7 \%$ 。年穿透雾水量与年降雨量呈负相关关系。 月穿透雾水量与月均最低气温呈显著的负相关, 与 月均相对湿度、月均 0:00 10:00 风速及月雾日数 呈显著的正相关。全年 $68 \% \pm 5 \%$ 的有雾天气里可 以收集到穿透雾水 $\left((0.38 \pm 0.27) \mathrm{mm} \cdot \mathrm{d}^{-1}\right)$, 且日穿 透雾水量、穿透雾水强度与气温和风速有显著的相 关性, 即气温越低、风速越大, 日穿透雾水量、穿透 雾水强度越大。

与世界其它大部分热带森林相比, 本区热带季 节雨林林冠穿透雾水平均占降水量 $4.9 \%$ 的值显然
很小(表 3), 略低于 Baynton(1989) 在波多黎哥 Pico Del Oeste 测定的 7.2\%、Cavelier 和 Goldstein（1989） 在委内瑞拉 Cerro Copey 测定的 $9.7 \%$ 和在巴拿马 Cordillcra Central 测定的 $8 \%$, 但高于 Cavelier 和 Goldstein (1989) 在委内瑞拉 E1 Zunmbador 测定的 3.5\%。 本研究的结果表明, 年林冠穿透雾水量与年降雨量 呈负相关关系 (图 1b), 这与 Cavelier 和 Goldstein (1989)在委内瑞拉和哥伦比亚热带森林的研究结果 相同。然而, Cavelier 和 Zhang (1996) 在巴拿马 Cordillcra Central 热带森林的研究并没有发现这种显 著的相关性。对本地区热带季节雨林而言, 雨水较 少的年份, 穿透雾水则较多 (图 1b), 较多的林冠穿 透雾水似乎是对雨水不足的一种补充, 这可能对热 带季节雨林内植物的正常生长具有更为重要的意 义。

降雨在林冠层再分配为 3 部分: 林冠截留、穿 
表 3 世界部分热带森林内年穿透雾水量和降雨量

Table 3 Annual fog throughfall and rainfall at some tropical forest sites in the world

\begin{tabular}{|c|c|c|c|}
\hline $\begin{array}{l}\text { 地点 } \\
\text { Location }\end{array}$ & $\begin{array}{c}\text { 穿透雾水 } \\
\text { Fog throughfall }(\mathrm{mm})\end{array}$ & $\begin{array}{c}\text { 降雨 }+ \text { 穿透雾水 } \\
\text { Rainfall + Fog throughfall }(\mathrm{mm})\end{array}$ & $\begin{array}{c}\text { 穿透雾水 } /(\text { 降雨 }+ \text { 穿透雾水 }) \\
\text { Fog throughfall } /(\text { Rainfall }+ \text { Fog throughfall })(\%)\end{array}$ \\
\hline E1 Zunmbador, Venezuela ${ }^{a}$ & 72 & 1983 & 3.5 \\
\hline Xishuangbanna, China ${ }^{\mathrm{b}}$ & 89 & 1807 & 4.9 \\
\hline Pico Del Oeste, Puerto Rico ${ }^{c}$ & 325 & 4530 & 7.2 \\
\hline Cordillcra Central, Panama ${ }^{\mathrm{d}}$ & 448 & 5696 & 8 \\
\hline Cerro Copey, Venezuela ${ }^{a}$ & 458 & 4461 & 9.7 \\
\hline Monteverde, Costa Rica ${ }^{\mathrm{e}}$ & 886 & 3191 & 28 \\
\hline Cordillcra Central, Panama ${ }^{\mathrm{d}}$ & 1130 & 3630 & 31 \\
\hline Santa Ana, Venezuela ${ }^{a}$ & 522 & 1630 & 32 \\
\hline Serrania de Macuira, Colombia ${ }^{a}$ & 796 & 1649 & 48 \\
\hline Cordillcra Central, Panama $^{\mathrm{d}}$ & 2295 & 3790 & 60 \\
\hline
\end{tabular}

a: Cavelier \& Goldstein (1989) b: This study c: Baynton (1989) d: Cavelier et al., (1996) e: Clark et al., (1998b)

表 4 热带季节雨林平均各季节水平降水量及与总降水量的比率 (1999 2002 年)

Table 4 Seasonal average horizontal precipitation and its ratio to total precipitationin the tropical seasonal rain forest $(1999-2002)$

\begin{tabular}{|c|c|c|c|c|}
\hline $\begin{array}{l}\text { 项目 } \\
\text { Items }\end{array}$ & $\begin{array}{c}\text { 雾季 } \\
\text { Foggy season }\end{array}$ & $\begin{array}{c}\text { 干热季 } \\
\text { Dry-hot season }\end{array}$ & $\begin{array}{c}\text { 雨季 } \\
\text { Rainy season }\end{array}$ & $\begin{array}{c}\text { 全年 } \\
\text { Whole year }\end{array}$ \\
\hline 截留雾水 Fog interception $(\mathrm{mm})$ & $104.8 \pm 7.9$ & $46.6 \pm 5.5$ & $98.9 \pm 8.4$ & $250.3 \pm 16.6$ \\
\hline $\begin{array}{l}\text { 截留雾水 }+ \text { 穿透雾水 Fog interception }+ \text { Fog } \\
\text { throughfall }(\mathrm{mm})\end{array}$ & $161.0 \pm 9.7$ & $67.2 \pm 6.2$ & $111.5 \pm 9.5$ & $337.9 \pm 18.3$ \\
\hline $\begin{array}{l}\text { (截留雾水 }+ \text { 穿透雾水)/总降水量 }(\text { Fog in- } \\
\text { terception + Fog throughfall }) / \text { Total precipitation } \\
(\%)\end{array}$ & $58.4 \pm 4.6$ & $51.9 \pm 3.0$ & $6.8 \pm 0.5$ & $16.4 \pm 1.0$ \\
\hline
\end{tabular}

总降水量 $=$ 截留雾水 + 穿透雾水 + 雨水 Total precipitation $=$ Fog interception + Fog throughfall + Rainfall 表内数据为平均值 \pm 标准差, 样本数 为 4 Entries are means \pm standard deviation $(\mathrm{SD})(n=4)$

透水和树干流。和降雨一样, 水平降水 (雾水) 同样 也应该有这 3 部分的再分配。据作者对该热带季节 雨林林冠截留雾水的研究 (刘文杰等, 2001b) 表明, 干热季林下可收集到雾滴的天气里, 林冠层可截留 雾水 $0.97 \mathrm{~mm} \cdot \mathrm{d}^{-1}$ 。如果每个雾日 (可收集到穿透 雾水) 以 $0.97 \mathrm{~mm}$ 的截留雾水量计算, 并忽略雾水的 树干流 (观测的 4 年间, 并未发现雾水沿树干到达地 面, 但仍会浸湿上部树干表面的少部分), 则全年林 冠共截留雾水 $(250.3 \pm 16.6) \mathrm{mm}$ (表 4), 占总降水 $(=$ 穿透雾水 + 截留雾水 + 雨量 $)$ 的 $12.1 \% \pm$ $0.8 \%$, 也即森林内全年水平降水为 $(337.9 \pm 18.3)$ $\mathrm{mm}$ (占总降水的 $16.4 \% \pm 1.0 \%$ ), 平均全年总降水 量可达 $2055.7 \mathrm{~mm}$ 。其中, $(250.3 \pm 16.6) \mathrm{mm}$ 的林 冠截留雾水无疑全部用到了林冠蒸发散中, 这将会 极大地改变林冠层的辐射分配和利用状况。因而, 森林内水平降水的研究也不能忽视林冠截留的这部 分雾水。另一方面, 本区干热季的降雨多为短时雷 阵雨 (刘文杰等, 1997), 对植物利用来说, 其有效性 无疑远低于缓慢滴落到林下土壤内的雾水。同时, 雾季和干热季白天持续到 11:00 左右的浓雾, 极大 地缩短了日照时数, 因而也相对减少了森林的蒸发 散量。因此, 雾及雾水导致的水分输入和输入方式
极大地弥补了本区降雨量的不足, 这对本区热带雨 林生态系统的健康生长和维持无疑是至关重要的。 显然,进一步的深入研究应该集中在热带雨林内的 植物如何利用和利用多少这部分雾水, 雾和雾水如 何影响森林蒸发散、光合作用、能量分配, 以及雾水 的化学效应上。

\section{参 考 文 献}

Asbury, C. E., W. H. McDowell, R. Trinidad-Pizarro \& S. Berrios. 1994. Solute deposition from cloud water to canopy of a Puerto Rican montane forest. Atmosphere Environment, 28: 1773 $\sim 1780$.

Baynton, H. W. 1989. The ecology of an elfin forest in Puerto Rico, 3. Hilltop and forest influences on the microclimate of Pico del Cesta. Journal of the Arnold Arboretum, 50:80 92 .

Cao, M. \& J. H. Zhang. 1996. Tree species composition of a seasonal rain forest in Xishuangbanna, Southwest China. Tropical Ecology, 37: 183 192.

Cavelier, J. \& G. Goldstein. 1989. Mist and fog interception in elfin cloud forest in Colombia and Venezuela. Journal of Tropical Ecology, 5:309 322 .

Cavelier, J., D. Solis \& M. A. Jaramillo. 1996. Fog interception in montane forest across the Central Cordillera of Panama. Journal of Tropical Ecology, 12:357 369.

Clark, K. L., N. M. Nadkarni, D. Schaefer \& M. L. Gholz. 1998a. Cloud water and precipitation chemistry in a tropical montane forest, Monteverde, Costa Rica. Atmosphere Environment, 
32: $1595 \sim 1603$.

Clark, K. L., N. M. Nadkarni, D. Schaefer \& M. L. Gholz. 1998b. Atmospheric deposition and net retention of ions by the canopy in a tropical montane forest, Monteverde, Costa Rica. Journal of Tropical Ecology, 14:27 45.

Dallard, G. J., M. H. Unsworth \& M. J. Harve. 1983. Pollutant transfer in upland regions by occult precipitation. Nature, 302 : $241 \sim 243$.

Gordon, C. A., R. Herrera \& T. C. Hutchinson. 1994a. Studies of fog events at two cloud forests near Caracas, Venezuela. II. Chemistry of fog. Atmosphere Environment, 28:323 337.

Gordon, C. A., R. Herrera \& T. C. Hutchinson. 1994b. Studies of fog events at two cloud forests near Caracas, Venezuela. I. Frequency and duration of fog. Atmosphere Environment, 28:317 $\sim 322$.

Grubb, P. J. \& T. C. Whitemore. 1966. A comparison of montane and lowland rain forest in Ecuador. II. The climate and its effects on the distribution and physiognomy of forest. Journal of Ecology, 54:303 333 .

Ingraham, N. L. \& R. A. Matthews. 1988. Fog drip as a source of groundwater recharge in Northern Kenya. Water Resource Research, 24: $1406 \sim 1410$.

Ishibashi, M. \& I. Terashima. 1995. Effects of continuous leaf wetness on photosynthesis: adverse aspects of rainfall. Plant, Cell and Environment, 18:431 438 .

Liu, W. J. (刘文杰)\& H. M. Li(李红梅). 1996. The fog resource in Xishuangbanna of China and its evaluation. Journal of Natural Resources (自然资源学报), 11:263 267. (in Chinese with English abstract)

Liu, W. J. (刘文杰)，H. M. Li(李红梅)\& W. P. Duan(段文 平). 1997. An agroclimatic analysis of the night rain resource in Xishuangbanna, China. Journal of Natural Resources (自然资 源学报), 12:330 335. (in Chinese with English abstract)
Liu, W. J. (刘文杰), K. Y. Zhang(张克映), G. M. Zhang(张 光明) , H. M. Li(李红梅) \& W. P. Duan(段文平). 2001a. The microclimate of dew and fog formation on canopy layer in the dry season in Xishuangbanna tropical rain forest. Acta Ecologica Sinica (生态学报), 21:165 170. (in Chinese with English abstract)

Liu, W. J. (刘文杰)，K. Y. Zhang(张克映)，C. M. Wang(王 昌命), H. M. Li (李红梅) \& W. P. Duan (段文平). 2001b. Canopy interception effect of dew and fog resources in dry season at a tropical rainforest in Xishuangbanna. Resources Science(资源科学), 23: 75 80. (in Chinese with English abstract)

Monteith, J. L.\& M. H. Unsworth. 1990. Principles of environmental physics. 2nd ed. London: Edward Arnold. $78 \sim 90$.

Oke, T. R. 1978. Boundery layer climates. New York: Wiley Press. 372.

Unsworth, M. H. \& A. Crossley. 1987. Capture of wind-driven cloud by vegetation. In: Coughtrey, P. J., M. H. Martin \& M. H. Unsworth eds. Pollutant transport and fate in ecosystems. Oxford, UK: Blackwell. $125 \sim 127$.

Weathers, K. C. \& G. E. Likens. 1997. Clouds in Southern Chile: an important source of nitrogen to nitrogen-limited ecosystems. Environmental Science and Technology, 31:210 213.

Weathers, K. C. \& G. E. Likens. 1988. Cloud water chemistry from ten sites in North America. Environmental Science and Technology, 22:1018 1026.

Zhang, K. Y. (张克映). 1963. An analysis on the characteristics and forming factors of climates in the south part of Yunnan. Acta Meteorologica Sinica(气象学报), 33:210 230. (in Chinese with English abstract)

Zhu, H. (朱华). 1992. Research of community ecology on Shorea chinensis forest in Xishuangbanna. Acta Botanica Yunnanica(云 南植物研究), 15:34 46. (in Chinese with English abstract)

责任编委: 周广胜 责任编辑: 姜联合 